\title{
Analysis of Urbanization of Rural Migrant Workers and Growth of Economics
}

\author{
Yong-Hong Zou ${ }^{1}$, Kai-Yuan Huang ${ }^{3}$ \\ 1, 3 College of Statistics, \\ Chengdu University of Information Technology, \\ Chengdu, China \\ E-mail: zyonghong@cuit.edu.cn
}

\author{
Jia-Tao Huang ${ }^{2}$ \\ 2 College of Statistics Jilin University of Finance and \\ Economics, \\ Changchun, China
}

\begin{abstract}
The cost measuring system of urbanization of rural migrant workers is established. The measurement models are built based on the system and the relative statistical indicators. Then the cost is calculated and compared with each other that migrant workers become citizens in Sichuan province and its 21 cities/states. At last the contribution measurement to the economics was done. The studies have shown that the personal cost is the highest one in the total cost over $45 \%$. In the item costs, the public cost in mountainous area is higher than in plain region. The enterprise cost is higher if the urbanization rate and average payment are higher in the area. The personal cost is higher if the average price of housing in the area is higher. It is over $3 \%$ of GDP come from the total cost of consumption of the urbanization of rural migrant workers in Sichuan. The main contribution is due to the personal cost consumption.
\end{abstract}

Keywords-rural migrant workers; urbanization; cost; contribution

\section{INTRODUCTION}

The situation is different from the foreign countries that the urbanization of farmers in China is from peasants to migrant workers and to citizens because of some identity conversion disorders faced them under the dual economy structure. This is a Chinese-path of urbanization of farmers, also is a Chinese-path to the emerging of urbanization. So it is important to study the economic significance of the urbanization of migrant workers.

\section{COST OF URBANIZATION OF RURAL MIGRANT WORKERS}

\section{A. Composition of Cost}

The cost of urbanization of rural migrant workers, in a broad sense, means two parts: one is the opportunity cost that the peasants come to the city while giving up the gain form the land. The other is the cost that the peasants are urbanized in city to make living and enjoy the public facilities. In fact, the cost in broad sense is the process cost of the whole process of citizenization. The cost of urbanization of rural migrant workers, in a narrow sense, is the costs of basic life and security to the city from countryside.

The cost in the described of the cost sharing mechanism in urbanization from agriculture in Chapter 8 of the first quarter in the state plan of new urbanization (2014-2020) is the cost in narrow sense. The cost of urbanization of rural migrant workers in this paper is kept consistent in the plan.

Detailed interpretation of the cost is: 1.the public cost, which is undertaken by the government, means the urbanized farmers enjoy the same service as the citizens in urban infrastructure construction and public utility services, etc. It concludes six costs. 2. The enterprise cost, which is undertaken by the firm which the migrant workers work in, means the cost same as insurance fee and training fee of the citizen workers.3. The personal cost, which is undertaken by the migrant workers themselves, means the cost maintaining the survival and development for the worker themselves. (See table I)

TABLE I. THE COST OF THE CITIZENIZATION OF MIGRANT WORKERS

\begin{tabular}{|c|c|c|}
\hline Total Cost & Part Cost & Item Cost \\
\hline \multirow{9}{*}{$\begin{array}{l}\text { The Total } \\
\text { Cost of the } \\
\text { Citizenization } \\
\text { of Migrant } \\
\text { Workers }(C t)\end{array}$} & \multirow{6}{*}{$\begin{array}{c}\text { Public } \\
\text { Cost }(G i)\end{array}$} & Infrastructure $\operatorname{Cost}(G l)$ \\
\hline & & Public Safety $\operatorname{Cost}(G 2)$ \\
\hline & & $\begin{array}{l}\text { Social Security and Employment } \\
\operatorname{Cost}(G 3)\end{array}$ \\
\hline & & Medical and Health Cost $(G 4)$ \\
\hline & & Housing Security Cost(G5) \\
\hline & & Energy Saving Cost $(G 6)$ \\
\hline & $\begin{array}{c}\text { Enterprise } \\
\operatorname{Cost}(E j)\end{array}$ & Social Insurance $\operatorname{coST}(E 1)$ \\
\hline & \multirow{2}{*}{$\begin{array}{l}\text { Personal } \\
\text { Cost }(P k)\end{array}$} & Living and Self-support $\operatorname{Cost}(P 1)$ \\
\hline & & Personal Housing Costs $(P 2)$ \\
\hline
\end{tabular}

III. MODELS AND INDEXES EXPLANATION OF URBANIZATION OF RURAL MIGRANT WORKERS

\section{A. Model Building}

According to the principle of component aggregation, the model is built based on table I. The current cost is measured that the rural migrant workers are urbanized followed the thought that will be operated simpler and easier. In this paper the generational differences are not considered.

$$
C_{t}=\sum_{i=1}^{6} G_{i}+\sum_{j=1}^{1} E_{j}+\sum_{k=1}^{2} P_{k}
$$

“ $i, j, k$ " are the item numbers. 


\section{B. Index Interpretations and Calculation Methods}

Per capita investment in fixed assets of non-agriculture people is chosen to measure the infrastructure cost $\left(\mathrm{G}_{1}\right)$. Personal housing cost is calculated separately because it is a big cost of the migrant workers. So the real estate investment should be taken out from the infrastructure cost. The index value may be higher than the actual value because the non-agricultural population is shared with and is not shared with the total population.

$$
G_{1}=\left(G_{n}-H_{n}\right) / U_{n}
$$

$G_{n}$ means the infrastructure cost.

$H_{n}$ means the real estate investment.

$U_{n}$ means non-agriculture population.

$\mathrm{n}$ means year ( $\mathrm{n}$ is agreed to in below).

Public Safety Cost in the local public financial expenditure is chosen to measure the index $G_{2}$. This part of cost is used for urban and rural. It cannot be split. So the index value may be lower than the actual value. This low maybe offset the high in $G_{l}$.

$$
G_{2}=S_{n} / R_{n}
$$

Sn means the public safety cost in the local public financial expenditure.

$R n$ means resident population (year-end). ( $R_{n}$ is agreed to in below).

Social Security and Employment Cost in the local public financial expenditure is chosen to measure the index $G_{3}$. This part of cost is used for urban and rural. It cannot be split. So the index value may be lower than the actual value. This low maybe offset the high in $G_{l}$.

$$
G_{3}=S E_{n} / R_{n}
$$

SEn meana Social Security and Employment Cost in the local public financial expenditure

Medical and Health Cost in the local public financial expenditure is chosen to measure the index $G_{4}$. This part of cost is used for urban and rural. It cannot be split. On the whole urban is higher than rural. So the index value may be lower than the actual value. This low can offset the high in $G_{l}$.

$$
G_{4}=M H_{n} / R_{n}
$$

$M H_{n}$ means the medical and health cost in the local public financial expenditure.

Housing Security Cost is used to ensure the housing difficulties for living by the government. The main security of this cost is used to the city, so the measurement of this index is that the housing security cost in the local public financial expenditure divided by the non-agriculture population.

$$
G_{5}=H S_{n} / U_{n}
$$

$H S_{n}$ means the housing security cost in the local public financial expenditure.

$U_{n}$ means non-agriculture population $\left(U_{n}\right.$ is agreed to in below).

Energy Saving Cost cannot be separate from urban and rural. So the measurement is for the whole society.

$$
G_{6}=E S_{n} / R_{n}
$$

$E S_{n}$ means the energy saving cost in the local public financial expenditure.

Enterprise Cost $\left(E_{j}\right)$ is the cost used for migrant workers' social insurance and training. The insurance is mandatory, so it is easy to calculate. But the training fees are not easy to count because the data is not easy to collect. So this index is only calculated about the endowment insurance, the medical insurance, the unemployment insurance, the industrial injury insurance and the maternity insurance which are paid by the enterprise. The pay proportions of enterprises are $20 \%, 6 \%$, $2 \%, 0.8 \%, 1 \%$. The total is $29.8 \%$ in the workers' wages.

$$
E_{j}=A P_{n} * 29.8 \%
$$

$A P_{n}$ means the average salary of the staff and workers in urban collective-owned unit. This wage is close to the migrant workers' wage. So it is chosen in this paper.

The index Per Capita Expenditure for Consumption of Urban Residents contains the factors as food, clothing, housing, transportation, teaching, entertainment, etc. These can ensure migrant workers' survival and life. The Housing Cost is singled out to calculate because it is a big cost for everyone. So the Residence Cost in the index is deducted according to the average level of entire province in the index. The average level of the Residence in the entire province is $17.5 \%$ in the Per Capita Expenditure for Consumption of Urban Residents in Sichuan province in 2014.

$$
P_{1}=P C_{n}-P C_{n} * 17.5 \%
$$

$P C_{n}$ means Per Capita Expenditure for Consumption of Urban Residents.

Buying house is an essential factor of personal cost in the process of urbanization of migrant workers. So it is measured by the indexes of Per Capita Housing Area of Urban Residents and Average Price of Residential Housing.

$$
P_{2}=P H_{n} * P P_{n}
$$

$P H_{n}$ means Per Capita Housing Area of Urban Residents. $P P_{n}$ means Average Price of Residential Housing. 


\section{MEASURE AND ANALYSIS OF COST BASED ON THE DATA OF SICHUSN PROVINCE}

\section{A. Measure the Cost}

Using the data of Sichuan Statistical Yearbook in the models (2) to (10) we can get the value of Part Cost. Then in the model (1) we can get the total cost value of Sichuan province and each city or state in 2014. (See Figure 1).

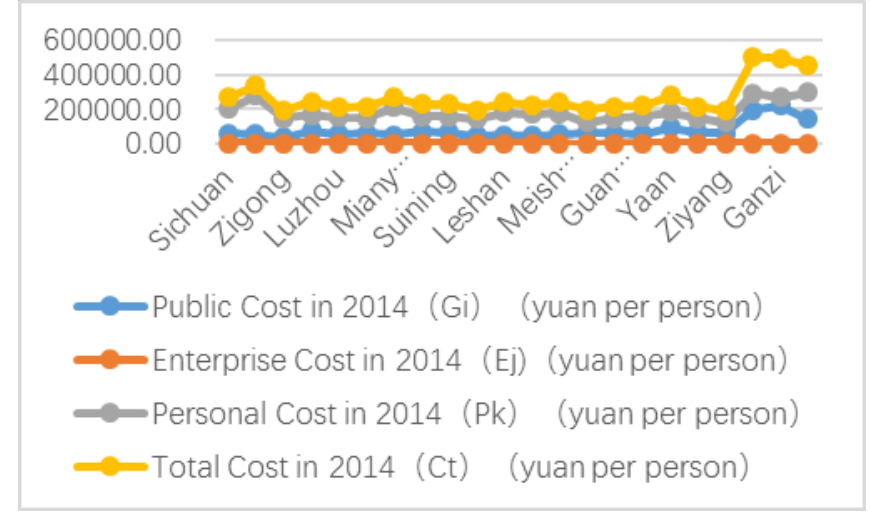

Figure.1. The cost of urbanization of migrant workers of Sichuan province and its cities or states in 2014

\section{B. Comparative Analysis of the Total Cost}

The average level in Sichuan province of the urbanization of rural migrant workers is 29.0 wanyuan per person. The cities which are over the average level are Chengdu, Yaan, Aba, Ganzi and Liangshan. Aba is the highest one; the cost is 58.5 wanyuan per person. The cities which are lower but over 25wanyuan per person are seven cities just like Panzhihua. The cities which the cost below 25wanyuan per person are nine cities just like Zigong.

The reason which the total cost in Chengdu is over the average level is the higher personal cost. It is over $70 \%$ of the total cost. The main reasons are high standard of living and high housing prices. The public cost is higher in the total cost in Aba, Ganzi and Liangshan. It is between 33\% and $45 \%$. The main reasons are higher investment in infrastructure and higher cost of public service. The three states are in the mountain area. There is a poorer regional environment in these areas. And they have lower economic development speed and weaker economic base. The lowest total cost is Zigong for its public cost; enterprise cost and personal cost are lower.

On the whole, the personal cost is the highest part in the total cost of the urbanization of rural migrant workers. It is all over $45 \%$ in every city or state in Sichuan. The highest city is Chengdu to $78.5 \%$. The lowest is Ganzi to $46.2 \%$.

\section{Comparative Analysis of the Part Cost}

The public cost average level in Sichuan province of the urbanization of rural migrant workers is 7.5 wanyuan per person. The cities which is over the average level are Panzhihua, Suining, Meishan, Yibin, Guangan,Dazhou, Yaan, Bazhong, Aba, Ganzi and Liangshan. Ganzi is the highest one; the cost is 26.4 wanyuan per person. The lowest is Zigong; the cost is 4.6 wanyuan per person.

The reason which the public cost is higher than the average level in six cities and three states is higher investment in infrastructure. These cities or states are in the mountain area in the edge of the basin. Infrastructure construction is difficult and this cost is much higher. So all the infrastructure construction cost in these cities or states is over $90 \%$. The highest is Liangshan to $96.1 \%$ of the total cost. The lowest is Zigong; its cost of $\mathrm{G}_{l}$ to $\mathrm{G} 6$ is all lower. So its public cost is the lowest in Sichuan.

The enterprise cost average level in Sichuan province of the urbanization of rural migrant workers is 1.3 wanyuan per person. There are nearly half cities or states of Sichuan are over the average level. They are Chengdu, Panzhihua, Deyang, Mianyang, Guangyuan, Neijiang, Meishan, Guangan, Aba and Ganzi. Aba is the highest one; the cost is 1.84 wanyuan per person.

The reason which the enterprise cost is higher than the average level in eight cities and two states is higher average salary of the staff and workers in urban collective-owned unit. So the part cost is higher affected by the measure of the index.

On the whole, look from the part costs, the public cost is obviously higher in the mountain areas than in the plain area. The enterprise cost is higher in the area where the urbanization rate is higher or the average salary is higher. The personal cost is higher where the average price of residential housing is high.

\section{ECONOMIC CONTRIBUTION OF URBANIZATION OF RURAL MIGRANT WORKERS}

\section{A. Cost Consumption of Urbanization of Rural Migrant Workers as a proportion of GDP}

Following the ideas and calculation model in 4.1 measurements will be done also as Sichuan province an example in this paper.

$$
\begin{gathered}
P t=G i / G D P * 100 \% \\
P t_{1}=G i / G D P * 100 \% \\
P t_{2}={ }^{E j} / G D P * 100 \% \\
P t_{a}=P k / G D P * 100 \%
\end{gathered}
$$

$P t$ means the total cost of urbanization of rural migrant 为 workers as a proportion of GDP.

$P t_{1}$ means the public cost as a proportion of GDP.

$\mathrm{Pt}_{2}$ means the enterprise cost as a proportion of GDP.

$\mathrm{Pt}_{3}$ means the personal cost as a proportion of GDP. 


\section{B. The number of Migrant Workers}

The first step is to measure the urban resident population.

$$
U_{r}=R_{n} * U_{r}
$$

$U_{r}$ means the urban resident population.

$R_{n}$ means the urban resident population (year-end).

$U_{r}$ means urbanization rate at that year.

The second step is to measure the number of migrant famers.

$$
U_{f}=\Delta U_{r}-P_{n}
$$

$U_{f}$ means the number of migrant famers in the process of new urbanization.

$\Delta U_{r}$ means the increase urban population compared with the last year.

$P_{n}$ means the natural growth population in city in that year.

The third step is to measure the number of migrant workers.

$$
W=V_{f} / 4
$$

In general, the whole family as a unit is urbanized in the process of new citizenization. There are fore people (one older, one couple and one child) is considered as in one family to be urbanized. One of them is the migrant worker (maybe the husband of the couple, the father of the child). So in the current period the migrant worker number is a quarter of the number of migrant famers in the process of new urbanization.

\section{The Measurement of the Cost Consumption of Urbanization of Rural Migrant Workers and the Measurement of Its Economic Contribution}

The total cost consumption from the urbanization of rural migrant workers in Sichuan province in 2014 is 87.962 billion yuan. Among them, the public cost consumption is
22.567 billion yuan. The enterprise cost consumption is 3.924 billion yuan. The personal cost consumption is 61.471 billion yuan. The total cost consumption from the urbanization of rural migrant workers as a share of GDP is $3.08 \%$. Among them, the public cost consumption as a share of GDP is $0.79 \%$, the enterprise cost consumption as a share of GDP is $0.14 \%$, the personal cost consumption as a share of GDP is $2.15 \%$. The contribution rate to GDP of the total cost consumption from the urbanization of rural migrant workers in Sichuan province in 2014 is $2.58 \%$.

There are twelve cities or states which the total cost consumption from the urbanization of rural migrant workers in 2014 as a share of the local GDP is over 3.08\%. They are Mianyang, Guangyuan, Suining, Nanchong, Meishan, Guangan, Dazhou, Yaan, Bazhong, Aba, Ganzi and Liangshan. There are thirteen cities or states which the contribution rate to the local GDP of the total cost consumption from the urbanization of rural migrant workers in 2014 is over 2.58\%. They are Deyang, Mianyang, Guangyuan, Suining, Neijiang, Nanchong, Meishan, Guangan, Yaan, Ziyang, Aba, Liangshan and Ganzi.

\section{REFERENCES}

[1] Liu Chuanjiang, Xu Jianling, "Study on the Process of Urbanization of Rural Migrant Workers in China", Beijing, 2008.

[2] Han Jun, "Promote the Urbanization of Rural Migrant Workers, Improve the Level of Urbanization", Found in Rural China, vol.4, pp.14-17

[3] Li Jiyang, Zou Yonghong, "Defect Analysis in the Connotation of the Urbanization of Farmers", Education, vol.12, pp. 287-289.

[4] Li Xiaomin, Tu Jianjun, Fu Zhengyi, Jia Linrui, Ha Lin, "The Cost of Citizenization from Migrant Workers in China", Economic Geography,vol.4, pp.133-140, 2016.

[5] Hu Guilan, Deng Zhaohui, Jiang Xueqing, "Cost Benefit Analysis of Citizenization from Migrant Workers", Issues in Agricultural Economy, vol.5, pp.83-87, 2013.

[6] Cao Bing, Guo Yuhui, "Social Cost Composition of urbanization of rural migrant workers", Economic Tribune, vol.8, pp.116-118, 2012.

[7] Zhou Xiangdong, "Research on the Cost Estimating and the Cost Sharing Mechanism of Urbanization of Rural Migrant Workers", Master Thesis, Chongqing Technology and Business University, China, 2012. 